\title{
CORRESPONDENCE
}

\section{Comment on "Partitioning of Polycyclic Aromatic Hydrocarbons to Marine Porewater Organic Colloids"}

SIR: In a recent paper appearing in this journal Chin and Gschwend (1) used a fluorescence quenching method to examine pyrene and phenanthrene binding to marine porewater organic colloids. The authors assumed that the drop in the measured emission signal resulted from

$$
F_{0}=F\left(1+K_{\mathrm{OC}}{ }^{\text {colloid }}[\mathrm{OC}]\right)\left(1+K_{\mathrm{uf}}[\mathrm{Q}]\right)
$$

interactions between the PAG fluorophore and colloids and from other chemical species (either organic and/or inorganic) present in the porewater that could statically and/or dynamically quench fluorescence emission. In the above Stern-Volmer equation, $F_{0}$ and $F$ refer to the PAH fluorescence in the absence and presence of the two different chemical quenchers, respectively, [OC] is the organic colloid concentration, $K_{O C}{ }^{\text {colloid }}$ denotes the colloidnonpolar organic compound (NOC) binding constant, [Q] is the concentration of noncolloidal quencher, and $K_{\text {uf }}$ represents the ultrafiltrate Stern-Volmer constant.

Colloid-nonpolar organic compound binding constants determined by use of eq 1 often yielded numerical values that were substantially lower than when the effects of noncolloidal quenchers were ignored. The authors were correct in recognizing that evaluation of realistical $K_{\mathrm{OC}}{ }^{\text {colloid }}$ values must take into account the effect of noncolloidal quenchers; however, their discussion fails to forewarn readers that eq 1 is not applicable under every set of circumstances which might be encountered. Specifically, eq 1 correctly describes the measured fluorescence emission in instances where the fluorophore can be quenched both by collisions and by complex formation with the same quencher or whenever the combined dynamic and static mechanism involves two different chemical quenchers (2). Equation 1 is not applicable to systems having two different static chemical quenchers or two different dynamic quenchers as one might naively believe based upon the authors' discussion.

This comment addresses the treatment of fluorescence data in systems having two different static chemical quenching agents (or, alternatively, two dynamic quenchers). Here, quenching is assumed to result from formation of two different nonfluorescent ground-state complexes, PAH-Q1 and PAH-Q2

$$
\begin{gathered}
\mathrm{PAH}+\text { quencher } 1 \rightleftharpoons \mathrm{PAH}-\mathrm{Q} 1 \\
K_{\mathrm{PAH}-\mathrm{Q} 1}=[\mathrm{PAH}-\mathrm{Q} 1] /([\mathrm{PAH}][\text { quencher } 1])
\end{gathered}
$$

each equilibria being described by an association/binding

$$
\begin{gathered}
\mathrm{PAH}+\text { quencher } 2 \rightleftharpoons \mathrm{PAH}-\mathrm{Q} 2 \\
K_{\mathrm{PAH}-\mathrm{Q} 2}=[\mathrm{PAH}-\mathrm{Q} 2] /([\mathrm{PAH}][\text { quencher } 2])
\end{gathered}
$$

constant. If both uncomplexed species are nonfluorescent, then the fluorescence signal is directly proportional to $[\mathrm{PAH}]_{\text {free }}$ A mass balance on the total molar concentration of the fluorophore

$$
\begin{aligned}
& {[\mathrm{PAH}] }=[\mathrm{PAH}]_{\text {free }}+[\mathrm{PAH}-\mathrm{Q} 1]+[\mathrm{PAH}-\mathrm{Q} 2] \\
&= {[\mathrm{PAH}]_{\text {free }}\left\{1+K_{\mathrm{PAH}-\mathrm{Q} 1}[\text { quencher } 1]+\right.} \\
&\left.K_{\mathrm{PAH}-\mathrm{Q} 2}[\text { quencher } 2]\right\}
\end{aligned}
$$

is used to relate the measured fluorescence emission intensity to

$F_{0}=F\left\{1+K_{\mathrm{PAH}-\mathrm{Q} 1}[\right.$ quencher 1$]+K_{\mathrm{PAH}-\mathrm{Q} 2}[$ quencher 2$\left.]\right\}$

the two association/binding constants.

Careful examination of eqs 1 and 5 reveals that these expressions differ significantly in terms of mathematical form and underlying fundamental principles. The two equations do give similar behavior whenever the quenching effects are small; i.e., $K_{\mathrm{PAH}-\mathrm{Q} 1}$ [quencher 1 ] $\ll 1$ and $K_{\mathrm{PAH}-}$ ${ }_{\text {Q2}}$ [quencher 2] $\ll 1$. The very small product of $K_{\mathrm{PAH}}$ Q1[quencher 1] $K_{\mathrm{PAH}-\mathrm{Q} 2}$ [quencher 2] can be arbitrarily added to the right-hand side of eq 5

$$
\begin{gathered}
F_{0}=F\left\{1+K_{\mathrm{PAH}-\mathrm{Q} 1}[\text { quencher 1] }+\right. \\
K_{\mathrm{PAH}-\mathrm{Q} 2}[\text { quencher 2] }+ \\
K_{\mathrm{PAH}-\mathrm{Q} 1} K_{\mathrm{PAH}-\mathrm{Q} 2}[\text { quencher 1][quencher 2] }\}
\end{gathered}
$$

and the resulting expression can be factored to yield

$$
\begin{aligned}
& F_{0}=F\left(1+K_{\mathrm{PAH}-\mathrm{Q} 1}[\text { quencher } 1]\right)(1+ \\
& \left.K_{\mathrm{PAH}-\mathrm{Q} 2} \text { [quencher 2] }\right)
\end{aligned}
$$

With statistical curve-fitting software being readily available, one should not have to invoke the arbitrary addition needed to transform eq 5 into eq 1 . Equation 5 is a bilinear expression in independent variables [quencher 1] and [quencher 2], and both association/binding constants are easily calculable from measured fluorescence intensity data.

Caution should be exercized in using fluorescence quenching methods to study the binding of organic compounds to water organic colloids, particularly in the case of polycyclic aromatic hydrocarbons (PAHs) and polycyclic aromatic nitrogen heteroatoms (PANHs). Previous measurements $(3-15)$ revealed that pyrene, benzo[ghi]perylene, ovalene, coronene, benzo[a]coronene, naphtho[2,3a] coronene, benzo[e]pyrene, naphtho$[8,1,2 a b c]$ coronene, dinaphtho $\left[8,1,2 a b c ; 2^{\prime}, 1^{\prime}, 8^{\prime} k l m\right]$. coronene, dibenzo[def,p]chrysene, phenanthro[5,4,3,2efghi]perylene, benzo[rst]pentaphene, 1-azabenz $[a]$ anthracene, 2-azabenz[ $a$ ]anthracene, 12-azabenzo[ $a]$ pyrene, phenanthro $[2,3 h]$ isoquinoline, phenanthro $[3,2 h]$ isoquinoline, and several other PAHs/PANHs exhibit probe character as evidenced by systematic variation of emission intensity ratios with solvent polarity. For the 25 (or so) probe molecules identified to date, a decreased fluorescence signal at a single wavelength does not necessarily indicate that quenching occurs. It is entirely 
possible that the fluorescence signal may be increasing at a second emission wavelength, as would be expected in the case of a probe molecule. To distinguish between fluorescence quenching and solvent polarity probe behavior, one should scan a fairly broad emission spectral region to ensure that the data are consistent. Finally, readers should not misconstrue the aforementioned comments as a criticism of the Chin-Gschwend paper, but rather as an informative discussion to facilitate analysis of PAHs/PANHs dissolved in environmental samples.

\section{Literature Cited}

(1) Chin, Y.-P.; Gschwend, P. M. Environ.Sci. Technol.1992, $26,1621-1626$

(2) Lakowicz, J. R. Principles of Fluorescence Spectroscopy; Plenum Press: New York, 1983; pp 257-271.

(3) Waris, R.; Rembert, M. A.; Sellers, D. M.; Acree, W. E., Jr.; Street, K. W., Jr.; Poole, C. F.; Shetty, P. H.; Fetzer, J. C. Appl. Spectrosc. 1988, 42, 1525-1531.

(4) Waris, R.; Rembert, M. A.; Sellers, D. M.; Acree, W. E., Jr.; Street, K. W., Jr.; Fetzer, J. C. Analyst 1989, 114, 195-199.

(5) Waris, R.; Acree, W. E., Jr.; Street, K. W., Jr.; Fetzer, J. C. Appl. Spectrosc. 1989, 43, 845-850.

(6) Acree, W. E., Jr.; Tucker, S. A.; Zvaigzne, A. I.; Street, K. W., Jr.; Fetzer, J. C.; Grutzmacher, H.-F. Appl. Spectrosc. $1990,44,477-482$.
(7) Acree, W. E., Jr.; Tucker, S. A.; Cretella, L. E.; Zvaigzne A. I.; Street, K. W., Jr.; Fetzer, J. C.; Nakasuji, K.; Murata, I. Appl. Spectrosc. 1990, 44, 951-957.

(8) Tucker, S. A.; Zvaigzne, A. I.; Acree, W. E., Jr.; Fetzer, J. C.; Zander, M. Appl. Spectrosc. 1991, 45, 424-428.

(9) Tucker, S. A.; Teng, I.-L.; Acree, W. E., Jr.; Fetzer, J. C. Appl. Spectrosc. 1991, 45, 186-189.

(10) Acree, W. E., Jr.; Tucker, S. A.; Fetzer, J. C. Polycyclic Aromat. Compd. 1991, 2, 75-105.

(11) Tucker, S. A.; Acree, W. E., Jr.; Tanga, M. J. Appl. Spectrosc. 1991, 45, 57-60.

(12) Tucker, S. A.; Acree, W. E., Jr.; Tanga, M. J. Appl. Spectrosc. 1991, 45, 911-915.

(13) Tucker, S. A.; Acree, W. E., Jr.; Tanga, M. J.; Zander, M.; Fetzer, J. C.; Tokita, S.; Hiruta, K.; Kitahara, K.; Nishi, H. Appl. Spectrosc. 1991, 45, 1188-1192.

(14) Tucker, S. A.; Acree, W. E., Jr.; Cho, B. P.; Harvey, R. G.; Fetzer, J. C. Appl. Spectrosc. 1991, 45, 1699-1705.

(15) Tucker, S. A.; Darmodjo, H.; Acree, W. E., Jr.; Fetzer, J. C.; Zander, M. Appl. Spectrosc. 1992, 46, 1260-1265.

Willam E. Acree, Jr.

Department of Chemistry

University of North Texas

Denton, Texas 76203-5068 